\title{
Educación emocional
}

\section{para familias y docentes}

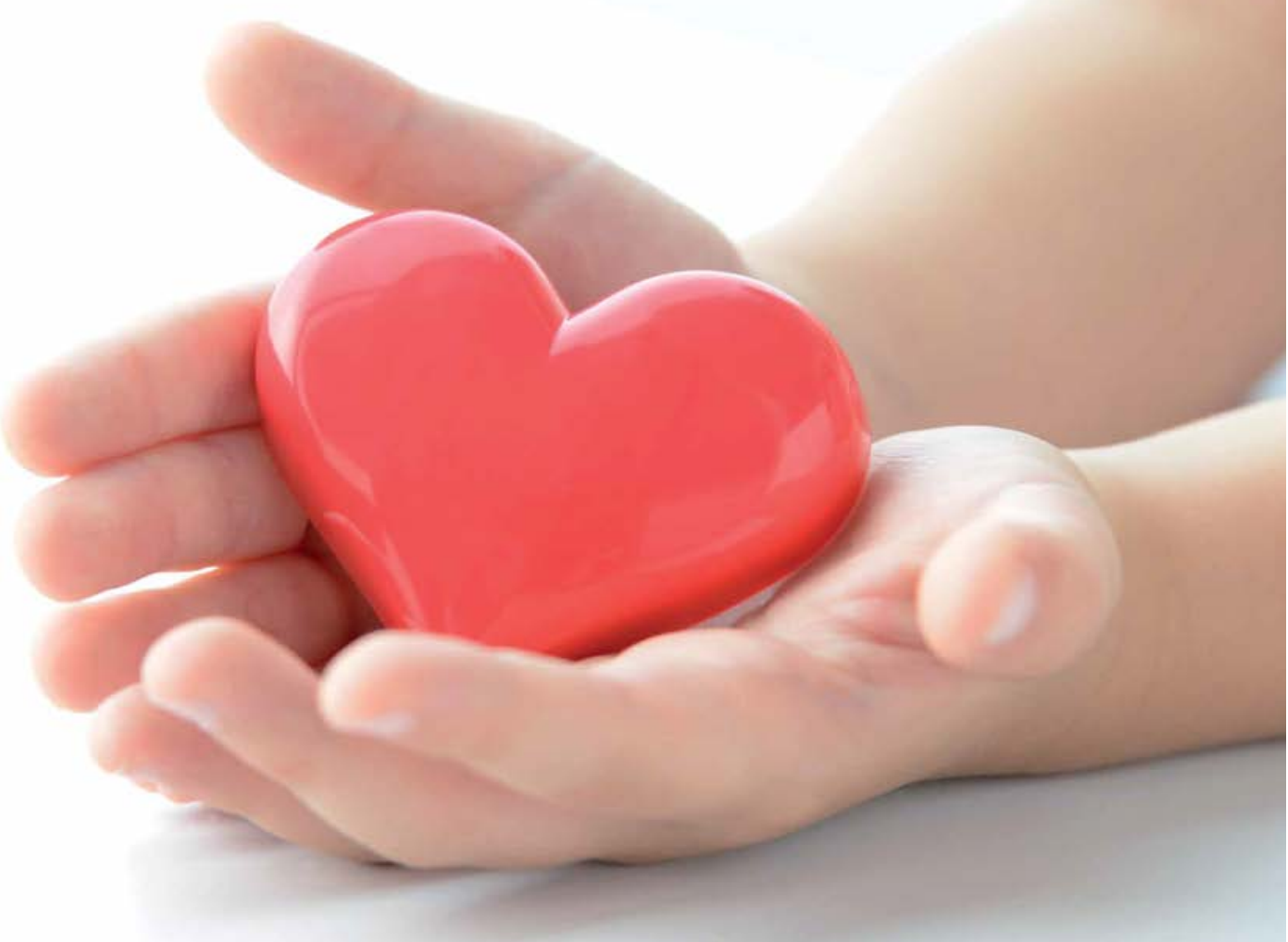

Tomar conciencia del amor, la gratitud, la generosidad, la alegría, la admiración, la curiosidad, que sentimos y que ofrecemos, es tan importante como saber regular las emociones negativas: la frustración, el enfado, la rabia, la vergüenza, todo ello, enriquecerá nuestra autoestima y las relaciones con los demás, así como el deseo de mejorar nuestro entorno familiar y social. Nuestros hijos y alumnos respirarán, a la vez que se nutrirán, de este bienestar. Como padres y maestros somos su ejemplo a seguir.

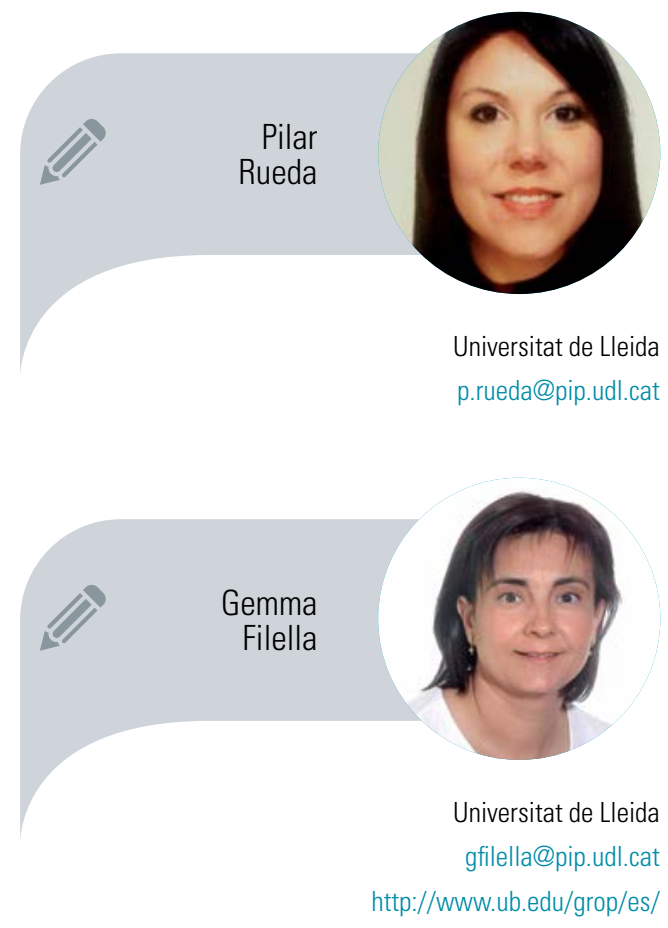


El concepto de educación es más amplio y superior que el de enseñanza y el de aprendizaje. Una vida moderna con sentido autocrítico necesita de la ética, ya que cuanta más libertad y cuanto más poder están en juego, más reflexión ética se requiere en todas las esferas de la vida. Las próximas líneas hablan del amor, la alegría, la esperanza, la ilusión, la sorpresa... es decir, de la grandeza de las emociones. Si queremos construir desde el campo educativo un proceso reflexivo de humanización, además de la ineludible tarea de vosotros como padres, la educación ética tiene que cultivarse desde la escuela en coherencia y con capacidad crítica para que los niños puedan juzgar por sí mismos la sociedad del presente y futuro próximo. Por ello, la educación en valores es un reto de nuestro Sistema educativo. Hay varios motivos que inducen a pensar en la necesidad de un programa de educación emocional conjunto para familia y escuela. Los motivos son muy variados, como por ejemplo, que las competencias emocionales son un aspecto básico del desarrollo humano y de la preparación para la vida, que los medios de comunicación transmiten información que el receptor debe aprender a procesar con una gran capacidad crítica y ética, por la necesidad de regular emociones para prevenir situaciones de riesgo (como pueden ser el consumo de drogas, conflictos intra- e interpersonales con agresividad), para permitir que los niños se familiaricen con estrategias que fomenten el bienestar, para permitir que el niño se equivoque y aprenda a ser más autónomo emocionalmente, para hacer comprender a los hijos que de la emoción no necesariamente debe derivarse un determinado comportamiento, sino que las emociones se pueden regular, etc... Tal y como defiende López GoNZÁLEZ (2013) un maestro es alguien que se ocupa del mundo interior del alumno. En el sentido más absoluto de la palabra es maestro de la interioridad, ya que el maestro provoca y acompaña el crecimiento del alumno, por tanto, también en su interioridad. Si el maestro tiene esta capacidad con sus alumnos, imaginad el poder que tenéis vosotros, los padres, con vuestros hijos.

\section{Educación emocional en el Sistema educativo}

Tal y como afirma el informe Delors (1996) "Frente a los numerosos desafíos del porvenir, la educación constituye un instrumento indispensable para que la humanidad pueda progresar hacia los ideales de paz, libertad y justicia social". Casi dos décadas después, en un escenario de replanteamiento de la educación del siglo XXI, el documento Repensar la educación (2015) de la UNESCO, fija la mirada en unas escuelas que no sólo se centren en los conocimientos, sino en las competencias emocionales y éticas de sus alumnos, puesto que se tendrán que enfrentar en el futuro a un mundo acelerado y lleno de contradicciones. Según la Ley Orgánica 8/2013, de 9 de diciembre, para la mejora de la calidad educativa (LOMCE; texto consolidado, última modificación 29 de julio de 2015) las habilidades cognitivas, siendo imprescindibles, no son suficientes; es necesario adquirir desde edades tempranas competencias transversales, como el pensamiento crítico, la gestión de la diversidad, la creatividad o la capacidad de comunicar, y actitudes clave como la confianza individual, el entusiasmo, la constancia y la aceptación del cambio.

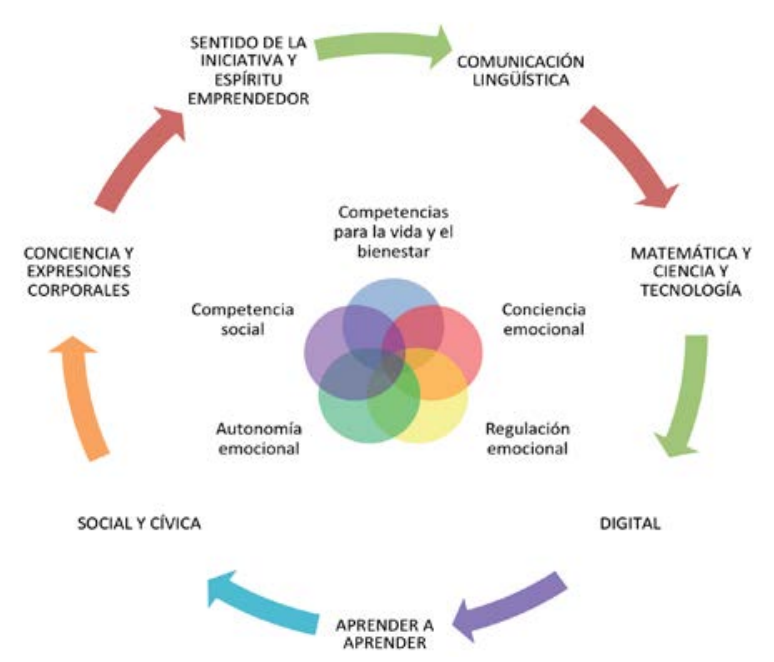




\section{ACTIVIDADES DE AULA}

La receta emocional

En esta actividad cada alumno debe imaginarse que es cocinero y debe escoger de los siguientes ingredientes emocionales un conjunto de emociones que formarán parte de su receta: felicidad, tristeza, tranquilidad, vergüenza, pasión, rabia. . . después deberán contestar individualmente a las siguientes preguntas:

$\checkmark \quad$ ¿Por qué has escogido estos ingredientes y no otros?

У Si tuvieras que elegir una receta para otra persona, ia quién elegirías? ¿Por qué?

$\searrow \quad$ ¿Qué ingredientes pondrías en la receta? ¿Por qué?

У Comparte tu receta con los demás y justifica la elección de ingredientes que has hecho.

Más información en: López-Cassà, E. (2011). Educar las emociones en la infancia (de 0 a 6 años), Reflexiones y propuestas prácticas. Madrid: Wolters Kluwer.

La educación inicial es cada vez más determinante por cuanto hoy en día el proceso de aprendizaje no se termina en el sistema educativo, sino que se proyecta a lo largo de toda la vida de la persona. La Recomendación (2002) 12 del Comité de Ministros a los Estados miembros sobre la educación para la ciudadanía democrática, de fecha 16 de octubre de 2002, señala que la educación para la ciudadanía democrática es esencial para promover una sociedad libre, tolerante y justa y que contribuye a defender los valores de la libertad, el pluralismo, los derechos humanos y el imperio de la ley, que son los fundamentos de la democracia. Uno de los principios en los que se inspira el Sistema educativo español es la transmisión y puesta en práctica de valores que favorezcan la libertad personal, la responsabilidad, la ciudadanía democrática, la solidaridad, la tolerancia, la igualdad, el respeto y la justicia, así como valores que ayuden a superar cualquier tipo de discriminación. Se contempla también como fin a cuya consecución se orienta el Sistema educativo español, la preparación para el ejercicio de la ciudadanía y para la participación activa en la vida económica, social y cultural, con actitud crítica y responsable y con capacidad de adaptación a las situaciones cambiantes de la sociedad del conocimiento. En este sentido, y para hacer evidente en el currículo estos ideales e intenciones se ha desarrollado la siguiente secuenciación de objetivos, contenidos y criterios de evaluación so- bre las competencias emocionales (conciencia emocional, regulación emocional, autonomía emocional, competencia social y competencia de vida y bienestar). De esta manera, se hace visible el currículo oculto de las mismas, comprendido en las siguientes competencias generales que establece la LOMCE: comunicación lingüística, sentido de la iniciativa y espíritu emprendedor, conciencia y expresiones culturales, matemática, ciencia y tecnología, digital, aprender a ser, social y cívica. Cada una de estas competencias generales, contempla tres ejes de actuación: saber, saber hacer y saber ser. En el presente documento, se justifica cómo el eje de actuación saber ser se fundamenta en las competencias emocionales. Por lo tanto, la competencia emocional adquiere el tratamiento y la consideración de competencia transversal.

Este planteamiento supone un cambio de mirada por parte del docente en particular y de toda la comunidad educativa en general. Esta nueva mirada impregnará una nueva manera de aprender, hacer y de ser durante el proceso de enseñanzaaprendizaje e implicará abordar el tratamiento de las competencias curriculares desde esta perspectiva humanista.

\section{¿Cómo educar las emociones en los niños? Las competencias emocionales}

Es importante que al niño, desde pequeño, se le enseñe pensando que la educación emocional tiene sentido desde el momento en que nacemos. Las emociones nos acompañan diariamente, forman parte de nosotros y deben educarse para poder crecer, desarrollarse y convivir mejor con uno mismo y con los demás.

Desde el grupo de investigación en Orientación psicopedagógica de la Universidad de Barcelona y de Lleida, contemplamos cinco competencias emocionales, que se desglosan en microcompetencias, las cuales se pueden alcanzar mediante actividades, tanto en la escuela como en casa.

Tal y como define Bisquerra y Pérez (2007), una competencia es la capacidad 
para movilizar adecuadamente un conjunto de conocimientos, capacidades, habilidades y actitudes necesarias para realizar actividades diversas con un cierto nivel de calidad y eficacia. Algunas características son que se pueden aplicar a las personas tanto de manera individual - grupal, implica unos conocimientos saberes, unas habilidades saber hacer y unas actitudes saber estar y saber ser integrados entre sí. Una competencia se desarrolla a lo largo de la vida, siempre se puede mejorar.

En concreto, las cinco competencias emocionales son las siguientes:

1. Conciencia emocional: es la capacidad para tomar conciencia de las propias emociones y de las emociones de los demás, incluyendo la habilidad para captar el clima emocional de un contexto determinado. Contempla, además, la toma de las propias emociones, dar nombre a las emociones, la comprensión de las emociones de los demás, etc.

2. Regulación emocional: es la capacidad para manejar las emociones de forma apropiada. Supone tomar conciencia de la relación entre emoción, cognición y comportamiento; tener buenas estrategias de afrontamiento; capacidad para autogenerarse emociones positivas, etc.

3. Autonomía emocional: la autonomía emocional la podemos entender como un concepto amplio que incluye un conjunto de características y elementos relacionados con la autogestión personal, entre las que se encuentran la autoestima, actitud positiva ante la vida, responsabilidad, capacidad para analizar críticamente las normas sociales, la capacidad para buscar ayuda y recursos, así como la autoeficacia emocional.

4. Competencia social: es la capacidad para mantener buenas relaciones con otras personas. Esto implica dominar las habilidades sociales básicas, capacidad para la comunicación efectiva, respeto por los demás, actitudes

\section{CAMIInAกDO JUnTOS}

Una propuesta de actividad de conciencia y regulación emocional para padres consiste en formularse a sí mismos las siguientes preguntas en diferentes momentos del día:

$\searrow \quad$ ¿Cómo me siento?

\ ¿Por qué me siento así?

$\searrow \quad$ ¿Cómo estoy manifestando lo que estoy sintiendo?

У ¿Esta emoción me ayuda en la situación y momento actual? ¿Qué estrategia puedo aplicar para mantenerla? 0 bien, ¿qué puedo hacer para cambiarla y sentirme mejor?

Esta actividad favorece la conciencia emocional puesto que se percibe, reconoce y expresa la emoción sentida. A la vez, se debe buscar una estrategia para poder regularla, como puede ser explicárselo a un amigo o familiar, realizar deporte...

Para poder educar las emociones de los hijos se debe comenzar por uno mismo. El ejemplo es el mejor ejercicio.

Más información en: BisquerRa, R. (CO0RD.) (2011). Educación Emocional, Propuestas para educadores y familias, Bilbao: Desclée de Brower.

Proceso de regulación emocional

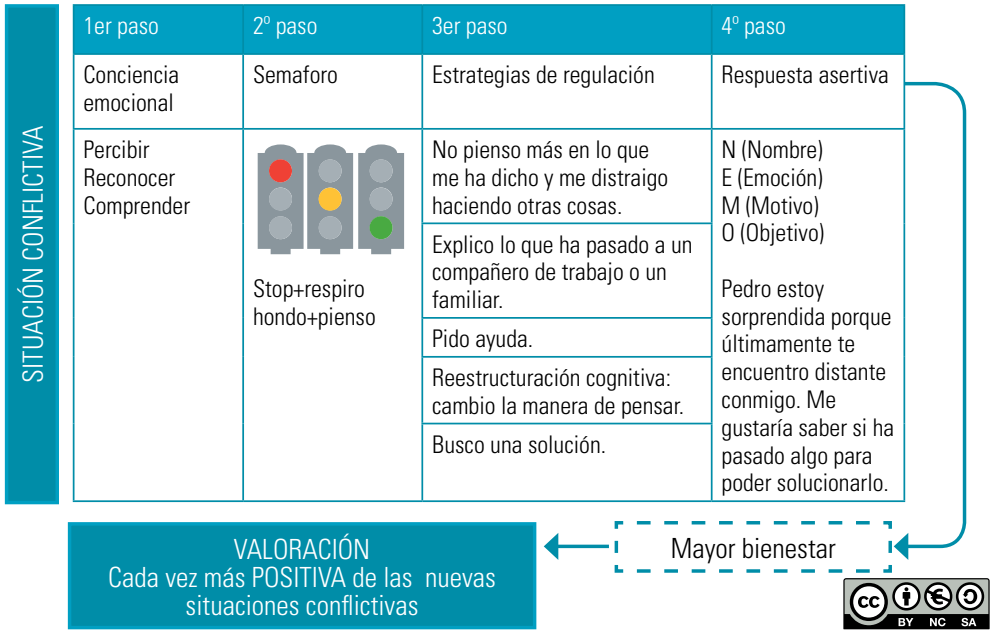

prosociales, asertividad, dominar la escucha activa, practicar la comunicación receptiva, compartir emociones, comportamiento prosocial y cooperación, asertividad, prevención y solución asertiva de conflictos, etc.

5. Competencias para la vida y el bienestar: son la capacidad para adoptar comportamientos apropiados y responsables para afrontar satisfacto-
Gemma Filella (Grupo de Investigación en Orientación Psicopedágociga (GROP Universitat de Lleida 


\section{IIII. AिQORA DE PROFESORES}

Para docentes la propuesta es un programa de educación emocional gamificado "Happy 8-12" y "Happy 12-16" para la mejora de la convivencia escolar.

Este programa es para Educación Primaria y Secundaria y tiene la finalidad de mejorar las competencias emocionales de los alumnos, así como su ansiedad y su rendimiento académico. Para ello, en la hora de tutoría se entrena el proceso de regulación emocional (ver imagen 1 ) en 25 situaciones conflictivas diferentes. A continuación se presenta un link del blog con más información:

http://emotionalsocialgames.blogspot.com.es/p/inicio.html

Trailer Happy: https://www.youtube.com/watch?v=8mwVbAs0J3c

Más información en: Filella, G. (2014)، Aprendre a Conviure. Barcelona. Barcanova.

\section{Competencia social}

\section{Autonomía
emocional \\ Autonomía
emocional}

\section{Competencias para la vida y el bienestar}

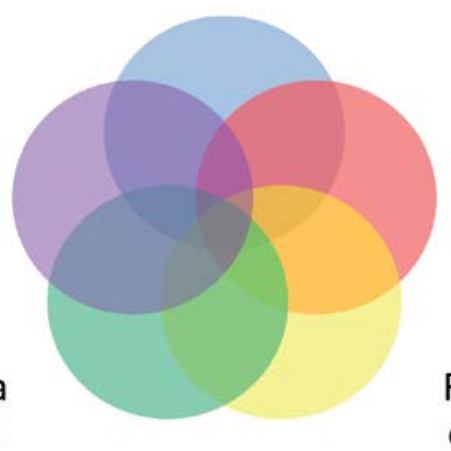

\section{Conciencia emocional}

\section{Regulación emocional}

入 Generar espacios de encuentro social con otros niños.

入 Crear materiales viajeros (cuentos, títeres...).

入 Compartir encuentros de educación emocional con más familias, maestros...

入 Permitir expresar, sin prohibiciones, las emociones que sientan los niños.

入 No eliminar las emociones negativas, todas son necesarias para la supervivencia (pero es necesario saber gestionarlas).

入 Contemplar el lenguaje emocional a través del cuerpo y de la palabra.

入 Hacer sentir valioso al niño, que es tan importante lo que hace como el cómo se siente cuando lo hace.

入 Permitir que los niños se familiaricen con estrategias que fomenten el bienestar.

入 Enseñarle a decir lo que quiere, lo que siente, lo que le gusta, lo que le disgusta... a expresarse sin tener que gritar, insultar o pegar.

\section{Consejos Prácticos}

A continuación, algunos consejos para vosotros como padres, educadores y maestros:

riamente los desafíos diarios de la vida, ya sean personales, profesionales, familiares, sociales, de tiempo libre, etc. Las competencias para la vida permiten organizar nuestra vida de forma sana y equilibrada, facilitándonos experiencias de satisfacción o bienestar. Para ello, se deben fijar objetivos adaptativos y realistas, tomar decisiones y asumir la responsabilidad que conllevan, buscar ayuda y recursos, bienestar emocional, generar experiencias óptimas en la vida profesional, personal y social, etc.

\section{Principios}

Una vez contempladas las cinco competencias emocionales, las cuales van a ser el eje vertebrador de las actividades con vuestros hijos o alumnos, se proponen una serie de principios para facilitar la puesta en práctica de las mismas: $\lambda$ Desde que nos levantamos hasta que nos acostamos sentimos emociones, pregúntate: ¿cómo te sientes?

त Ayuda al niño a tomar conciencia de sus emociones. El secreto está en expresarlas (hablando, escribiendo, dibujando, pintando...).

入 Ayuda al niño a expresar las manifestaciones de las emociones, tanto las negativas como las positivas. Por ejemrealizar aquello que tanto querías?

入 Responde abiertamente a los sentimientos de malestar, para que aprenda a expresar su malestar sin vergüenza y a responder con empatía a las necesidades de los otros.

$\boldsymbol{\lambda}$ Intenta solucionar juntos los problemas.

入 Potencia su capacidad crítica comentando y debatiendo diferentes situaplo: ¿estás triste porque no has podido 
ciones cotidianas (noticias, cuentos, actividades diarias...).

7 Expresar todo lo que nos hace sentir: me encanta que seas mi hijo, estoy muy orgulloso de ti, me gusta abrazarte...

- No despreciar ni desaprobar los sentimientos del niño, y especialmente los sentimientos o emociones negativas.

7 No temáis compartir vuestros sentimientos con los del niño y permitid que os vean como personas completas, con virtudes y defectos, que sienten, dudan y necesitan su comprensión, igual que necesitan la vuestra.

$\boldsymbol{\lambda}$ No olvides que siempre eres su ejemplo a seguir.

\section{Reflexión}

Como seres humanos somos inteligencia y pero también seres emocionales. Desde los tres años de edad opera en nuestro cerebro una intrincadísima red de 100 millones de neuronas para juntar ambos procesos. Por muchos años la humanidad sólo se ocupó del aspecto intelectual, olvidándose de la parte que ocupaba más espacio en el cerebro que es el aspecto emocional. La atención a las emociones debe ser prioritaria para la mejora de los procesos de enseñanza-aprendizaje, así como lo es para nuestra salud física y mental. La educación emocional es preventiva, por ello, cuanto antes se entrenen las competencias emocionales, mucho antes se logrará alcanzarlas y así tener un mayor bienestar y calidad de vida. Los riesgos de una falta de control emocional trascienden a la situación educativa y pueden llevarnos fácilmente a caer en la ansiedad, en la excitación y depresión, que son las puertas de entrada hacia las enfermedades.

Es indudable que la situación mental y emocional influye en nuestra situación física, en cambio, una actitud mental y emocional positiva puede constituirse en una verdadera coraza que nos permita defendernos para enfrentar al mundo y para evitar las agresiones físicas a nuestro organismo. Imaginemos a un ser humano sin emociones: en el mejor de los casos mostraría un estado intelectual frío y en el peor de los casos, sería un psicópata. Las emociones nos humanizan; será maravilloso cuando podamos controlarlas en sus excesos y disfrutarlas plenamente cuando llegan sus momentos. Ésta es la clave de la educación emocional.

A lo largo de todo el texto se ha abordado el porqué de la educación emocional, qué es exactamente la educación emocional, cómo trabajarla con vuestros hijos o alumnos, ¿pero qué sucede con nosotros mismos, con los adultos? Exactamente lo mismo. Somos adultos, pero también fuimos niños. Todo lo expuesto anteriormente podemos aplicarlo a nosotros mismos, de esta forma nos permitirá madurar emocionalmente junto con hijos o alumnos •

\section{(C) DARr SABEr MấS}

Barceló, T. (2013). La sabiduría interior. Bilbao: Desclée de Brower.

Bisquerra, R. (coord.) (2011). Educación Emocional. Propuestas para educadores y familias. Bilbao: Desclée de Brower.

FelBer, C. (2012). La economía del bien común. Barcelona: Deusto.

FILELLA, G. (2014). Aprendre a conviure. Barcelona: Barcanova.

GARDNER, H. (2011). Verdad, belleza y bondad reformuladas. La enseñanza en las virtudes del siglo XXI. Barcelona: Paidós.

González, C. (2013). Veintitrés maestros, de corazón: un salto cuántico en la enseñanza. Bilbao: Desclée De Brouwer.

López Argelo, V. L. (2005). La comunicación en familia. Más allá de las palabras. Madrid: Síntesis.

Punset, E. (2012). Una mochila para el universo. Barcelona: Destino.

Vallés Arándiga, A. (2000). La inteligencia emocional de los hijos. Cómo desarrollarla. Madrid: EOS.

HEMOS HABLADO DE

Sistema educativo; educación emocional; bienestar; competencias emocionales.

Este artículo fue solicitado por PADRES y MAESTROS en marzo de 2016, revisado y aceptado en octubre de 2016. 